\title{
The Role of Emotion Regulation Strategies and Behavioral Activation System (BAS) in Social Adjustment of Adolescents With Conduct Disorder
}

\author{
Soheila Imanparvar ${ }^{1} \&$ Meysam Ghasemi ${ }^{2}$ \\ ${ }^{1}$ Department of Educational Psychology, Ajabshir Branch, Islamic Azad University, Ajabshir, Iran \\ ${ }^{2}$ Department of Clinical Psychology, Ardabil Branch, Islamic Azad University, Ardabil, Iran \\ Correspondence: Soheila Imanparvar, Department of Educational Psychology, Ajabshir Branch, Islamic Azad \\ University, Ajabshir, Iran. E-mail: soheila.e1361@gmail.com
}

Received: April 23, 2016

Accepted: May 15, 2016

Online Published: July 4, 2016

doi:10.5539/mas.v10n10p75

URL: http://dx.doi.org/10.5539/mas.v10n10p75

\begin{abstract}
The purpose of this research was to explain the role of emotion regulation strategies and behavioral activation system (BAS) in social adjustment of adolescents with conduct disorder. The method of study is descriptive-correlation. The statistical population included all junior high school students in Ardabil in 2016. The sampling was conducted by the multistage cluster method and then 50 subjects with conduct disorder were selected as the sample group using this method. Data of the present study were collected using Rutter behavioral disorders questionnaire (form B), students adjustment questionnaire, emotion regulation questionnaire and activation system and behavioral inhibition questionnaire. The obtained data were analyzed using Pearson correlation coefficient test and regression analysis using SPSS software. The findings showed that there is a significant relationship between social adjustment and behavioral activation (BAS) and emotion regulation system $(\mathrm{P}<0.05)$. Also, the results of regression analysis showed that behavioral activation and emotion regulation system can significantly explain $16 \%$ variances in social adjustment of students with conduct disorders. Accordingly, it can be concluded that behavioral activation and emotion regulation system plays a role in social adjustment.
\end{abstract}

Keywords: emotion regulation, behavioral activation system (BAS), social adjustment, conduct disorder

\section{Introduction}

Conduct disorder is one of the most common disorders in childhood and adolescence and a major reason for referral to treatment centers. This disorder has a frequent and continuous behavioral pattern whereby basic rights of others or social norms and regulations are violated according to the age (America Psychiatric Association, 2013). Children with conduct disorder are highly vulnerable to rejection by peers, poor academic performance, increased aggressive behavior, and they are also prone to mood disorders, substance abuse and delinquency and antisocial personality disorder in adulthood (Saduk \& Saduk, 2003). The prevalence of conduct disorder has increased in the past decades and one-year prevalence is expanding among the population from $2 \%$ to more than $10 \%$ with an average of $4 \%$; it seems that the prevalence of conduct disorder is stable in several countries with racial and ethnic differences. The prevalence increases from childhood to adholescence and it can be observed among men higher than women (America Psychiatric Association, 2013). The most important effects of conduct disorder include aggression, lack of social adjustment, poor interpersonal relationships, rejection from peer groups, academic deficiencies, lack of problem-solving skills and deficits in attention and thinking which among them, the lack of social adjustment is one of the most important issues involved with children with conduct disorder. It seems that children with conduct disorder misinterpret the mild and fair interpersonal behaviors of others because of their hostile willingness. Children and adolescents with conduct disorder have some biases in selective attention and remembering; they consider the hostile social cues rather than the positive social ones in their interpersonal interactions ( Mohammad Ismael, 2005).

Most experts believe that instead of a single cause, a variety of factors put people at risk for disruptive disorders that in general these factors include a set of characteristics and genetic tendencies, biology or personality of the child, ineffective parenting and environmental conditions (Kheiri, 2009). Emotional regulation strategies such as 
psychological components have become the grounds for extensive researches including disorders in childhood and adolscence (Garnefski, 2009). Emotional regulation refers to the strategies affecting what emotions individuals experience, when they do them and how they express them (Gross, 2007). The emotional regulation strategies are inherent aspects of tendencies related to the emotional responses. According to Garnfsky (2006), emotional regulation strategies are actions indicating the ways of coping with stressful situations or mishaps. Different studies have shown that children and adolescents with externalized disorders and disruptive behaviors such as aggression and hyperactivity use more maladaptive emotional regulation strategies (Pourfaraj, 2011) and they have defect and failure in applying the emotional regulation strategies (Barkley \& Fischer , 2010). The findings of this research indicate that children and adolescents in the age group of 7 to 16 years old with externalized disorders and disruptive behaviors have some difficulties in organizing the emotional experiences, evaluating own and others' emotions and emotional expression in different situations appropriately and they use less positive skills of emotional regulation strategies such as planning, re-evaluation and acceptance (Spencer, 2011).

The results of research by Biederman et al. (2012) showed that children and adolescents in the age group of 6 to 18 years with hyperactivity have a major disability in functions related to emotional self-regulation, so that they have some main and serious problems to understand and control their emotions and feelings.

Another psychological component involved and influential in the field of disorders in childhood and adolescence is behavioral activation system. Studying the brain systems involved in a variety of behaviors and mental and emotional experiences, Gary stated that emotions are regulated through different parts of the brain. Gary named the system involved in variety of positive emotions as "tendency system"and the system involved in anxiety as "behavioral inhibitation system or stop system" ( Han et al., 2009). In "reinforcement sensitivity theory (RST)", Gary and Mac Nagtun (2000) raised three different brain - behavioral systems underlying personality differences, including: 1) behavioral inhibition system (BIS) 2) behavioral activation system (BAS) 3) fight-flight system (FFS). Behavioral activation system (BAS) activates reward-seeking behavior, feeling of pride and hope of reward in spite of the danger or threat; it is known as the arousal system and consists of two components including approach and active avoidance (Corr, 2004). BAS responds to the conditional stimuli of reward and the lack of punishment. Activity and increased sensitivity of this system leads to invoke positive emotions, approach and active avoidance (Gary and Mac Nagtun, 2000). The nervous anatomy bases of this system which are structurally related to the dopaminergic brain pathways and cortico striato pallido-thalamic circuits (CSPT) ( Fulyz, 1980) are located in the prefrontal cortex, amygdala, and basal ganglia ( Havigh, 2006). BAS sensitivity indicates impulsivity of the person (Gary, 1995). In this regard, the most attention is focused on behavioral activation system and the most findings about activity of this system in human are derived from studies related to the neurotransmitter dopamine. Release of dopamine in the dopaminergic pathways associated with the BAS system is accompanied with flowing motor programs of this system (Feldan, 1991). Studies show that BAS is disrupted in the delinquent individuals ( Hamzlou \& Mashhadi, 2010) and lack of control of behavioral activation leads to involuntary or impulsive behaviors ( Mashhadi et al, 2009). The studies also show that overcoming the behavioral inhibition by BAS causes impulsive behaviors, inability to self-control and strengthen the person's risky behaviors ( Favelz, 2001; Witakou \& Rogerz, 2001). The studies also show that there is an inverse relationship between BAS activities with social interactions (Nathan et al., 2010) and social and emotional functioning of children (Adam et al., 2013). In a research, Andrew and colleagues (2009) showed that BAS with anger arousal and aggressive reactions predicts anger states which it can cause a reduction in social adjustment of these individuals. In this regard, the present study was conducted to investigate the role of emotion regulation strategies and BAS in social adjustment of adolescents with conduct disorder.

\section{Method}

\subsection{The Research Method, Population, Sample and Sampling Methods}

The method of the present research is descriptive-correlation and the researcher sought to examine the role of emotion regulation strategies and behavioral activation system in social adjustment of adolescents with conduct disorder. In this study, emotion regulation strategies and behavioral activation system have been considered as predictor variables while social adjustment has been considered as the criterion variable. The statistical population included all junior high school students in Ardabil in the academic year 2015-2016. In the present study, the sampling was conducted by the multistage cluster method by which and after the necessary coordinations, 4 schools and 4 classes per school were selected from the school districts 1 and 2 in Ardabil and in total 25 subjects were selected randomly which included 400 students totally. Then, Rutter behavioral disorders questionnaire (form B) was presented to the teachers of these students and it was answered by them, then students with conduct disorder were identified using this method and 50 subjects were selected randomly as the 
sample group.

\subsection{The Following Tools were Used to Collect Data}

A scale of behavioral inhibition/activation system: This scale was developed by White and Carver to assess individual differences in sensitivity to behavioral inhibition and behavioral activation system (Gary, 1995). This scale has 24 items and participants respond to these questions in a 4-point Likert scale from "not true" (1) to "completely true" (4). Roussion and colleagues (2009) reported the internal consistency of behavioral inhibition up to 0.72 and its discriminant validity with anxiety up to 0.55 . They reported Cronbach's alpha coefficient of the subscales inhibitation and activation about 0.78 and 0.81 , respectively (Gary, 1995).

Students adjustment questionnaire: this questionnaire has been developed by Sinha and Singh (1993; quoted in Narimani et al, 2011) and it has been translated and written by Karami (1998). This questionnaire has 60 items; it has been designed as Yes and No and separates students with good adjustment from ones with poor adjustment in three areas of adjustment (social, emotional and academic). In this questionnaire, score 0 is given to responses indicating adjustment in all three areas, otherwise score 1 is considered for them. Using the split-half and test-retest methods, reliability coefficient of this test has been reported up to $0 / 95$ and $0 / 93$, respectively. In his research, Stefoladchang (2006) has reported test-retest coefficient and Kuder Richardson coefficient of this questionnaire about $0 / 89$ and $0 / 82$, respectively. In the present study, reliability coefficient was obtained up to $0 / 81$ using Cronbach's alpha test.

Emotion cognitive regulation questionnaire (short version): This questionnaire has been developed by Garnefsky (2006) which includes 18 items with 9 strategies; acceptance, positive attention, positive attention to valuation, remarketing, planning, self-blame, blaming others, rumination and catastrophizing. Items are answered on a Likert scale graded from "almost never to almost always". For subscales, Cronbach's alpha coefficient is in the range of $0 / 73$ to $0 / 80$ and retest reliability coefficient has been obtained in the range of $0 / 41$ to $0 / 59$.

Rutter behavioral disorders questionnaire (form B): Rutter questionnaire (form B) contains 26 items filled out by the teacher. This questionnaire measures four components (normal, conduct disorder, emotional disorder, inseparable). The students who have gained a total score 9 or higher in Rutter behavioral disorders questionnaire and their score for conduct disorder is greater than the score of emotional disorder are diagnosed as students with conduct disorder ( Narimani, Abolqasemi, 2006). In a research, Abolqasemi (2004) applied this questionnaire for 60 normal and abnormal students. Reliability coefficients for spilt-half and Cronbach's alpha of this questionnaire were obtained 0.83 and 0.91 , respectively.

\subsection{Method}

In this study, the data collection method was used in both levels of library method and also field method (the questionnaire data collection). In order to collect the questionnaire data, first it was performed the necessary coordinations with Ministry of Education in Ardebil and the intended school administrators and then sampling was conducted using the multistage cluster sampling method. The sampling process was in such a way that 4 schools and 4 classes (from each school) were selected from the school districts 1 and 2 in Ardabil and a total of 25 subjects were selected randomly which included 400 students totally. Then, Rutter behavioral disorders questionnaire (form B) was provided to the teachers of these students and it was answered by them; The students with conduct disorder were identified using this method and then the research objectives were explained for them. The students who had declared their readiness to participate in the research were checked using the fifth manual of diagnosis of psychiatric disorders and then, 50 students were selected as the sample group; And the questionnaires of social adjustment, emotion regulation and brain-behavioral systems were provided to these individuals and were completed in the presence of the researcher and finally, the obtained data were analyzed using SPSS statistical software.

\section{Results}

Total of respondents studied in this research was 50 subjects who were studying in the first grade of high school. According to the demographic findings, 17 students were 13 years old, 11 students were 14 years old and 22 of these individuals were 15 years old. Also, 19 of them were femal and 31 of them were male. According to the obtained results, 18 students were studying in the first grade of high school, 16 students were studying in the second grade of high school and 16 students were doing in the third grade of high school. The results of descriptive and inferential findings from the obtained data have been presented in the following tables: 
Table 1. Mean and Standard Deviation of scores of emotion regulation, BAS and social sdjustment

\begin{tabular}{lll}
\hline Variable & Mean & SD \\
\hline Emotion regulation & 53.10 & 8.20 \\
BAS & 44.88 & 4.76 \\
Social adjustment & 13.25 & 3.35 \\
\hline
\end{tabular}

The results of Table 1 show that the mean and (SD) of scores of emotion regulation, BAS and social adjustment are obtained equal to $53.10(8.20), 44.88$ (4.76) and $13.25(3.35)$, respectively.

Pearson correlation coefficient test was used to investigate the relation of social adjustment with emotion regulation and behavioral activation in children with conduct disorder that its results have been reported in the following tables:

Table 2. Correlation coefficient of emotion regulation, BAS with social adjustment

\begin{tabular}{lll}
\hline Variable & Statistics & Social adjustment \\
\hline Emotion regulation & Correlation coefficient & 0.47 \\
& significance level & 0.000 \\
BAS & Correlation coefficient & 0.31 \\
& significance level & 0.01 \\
\hline
\end{tabular}

As table 2 shows, it can be said that there is a significant positive correlation between $(p<0.01)$ social adjustment and emotion regulation $(\mathrm{r}=0.47)$ and BAS $(\mathrm{r}=0.31)$ in a significant level of $0 / 05$ with $95 \%$ confidence level.

Table 3. Results of multivariate regression analysis of emotional adjustment and behavioral activation system to predict social adjustment

\begin{tabular}{|c|c|c|c|c|c|c|c|c|}
\hline Model & \multicolumn{2}{|l|}{ ss } & Df & \multicolumn{2}{|l|}{ Ms } & $\mathrm{F}$ & \multicolumn{2}{|l|}{$\mathbf{P}$} \\
\hline Regression & \multicolumn{2}{|c|}{107.49} & 2 & 53.74 & & \multirow[t]{3}{*}{5.49} & \multirow[t]{3}{*}{0.007} & \\
\hline Remaining & & & 47 & \multirow{2}{*}{\multicolumn{2}{|c|}{9.78}} & & & \\
\hline Total & \multicolumn{2}{|c|}{664.25} & 49 & & & & & \\
\hline Predictor variables & $\mathbf{R}$ & Rs & ARS & \multirow{2}{*}{\multicolumn{2}{|c|}{$\begin{array}{l}\text { Non-standardized } \\
\text { coefficients }\end{array}$}} & Standardized & $\mathbf{T}$ & sig \\
\hline \multirow{2}{*}{ Constant } & & & & & & coefficients & 585 & 0000 \\
\hline & & & & 30.32 & 5.17 & - & 2.06 & 0.04 \\
\hline \multirow{2}{*}{ Emotion regulation } & 0.40 & 0.16 & 0.13 & 0.11 & 0.05 & 0.25 & 2.78 & 0.007 \\
\hline & & & & 0.23 & 0.08 & 0.33 & 5.85 & 0.000 \\
\hline BAS & & & & & & & & \\
\hline
\end{tabular}

In order to determine their effects, each of the variables of emotional adjustment and behavioral activation system as "predictor variables" and social adjustment as "dependent variable" were analyzed in the regression equation. As it can be seen in Table 3, the observed level of $\mathrm{F}$ is significant $(\mathrm{p}<0.007)$. The results show that the students with conduct disorder explain $16 \%$ of variances of social adjustment. According to $\beta$ values, emotion regulation $(\beta=0.25)$ and BAS $(\beta=0.33)$ can predict significantly the variations related to social adjustment in students with conduct disorder.

\section{Discussion}

Conduct disorder is a sustainable set of behaviors formed over time and it is characterized by symptoms such as cruelty to animals and people, destruction of properties, deceit, deception, lying, stealing, violating the rights of others. Such problems lead to serious problems for patient, family and the community ( Boris \& Dalton, 2004). No single factor can explain the child's antisocial behavior and conduct disorder, but several bio-psycho-social factors are involved in this disorder. In general, the worst prognosis for conduct disorder is related to the children who develop the symptoms in younger ages, have a greater number of symptoms and show often these symptoms (Saduk \& Saduk, 2008; translated by Arjomand et al, 2011). Conduct disorder affects a person's daily 
life including social adjustment. According to this, the results of the present study were to investigate the role of emotional regulation strategies and behavioral activation system (BAS) in social adjustment of adolescents with conduct disorder.

\subsection{The First Hypothesis was that Emotion Regulation Strategies Play a Key Role in Social Adjustment of Adolescents with Conduct Disorder}

Pearson correlation test and regression analysis were used to test this hypothesis which it was obtained a significant positive correlation $(\mathrm{p}<0.01)$ between social adjustment and emotion regulation $(\mathrm{r}=0.47)$. The results of regression analysis and $\beta$ values show that emotion regulation $(\beta=0.25)$ can predict significantly the variations related to social adjustment in the students with conduct disorder. The obtained results are consistent with the results of researches by Garnefsky (2006), Pourfaraj ( 2011), Berkeley (2010), Spencer (2011) and Biderman et al (2012). Emotion exists in the form of mental, purposeful biological and social phenomena. In this sense, the emotion is a mental feeling which makes us feel a special state such as anger or happiness. Emotions are also the biological reactions. They are responses mobilizing energy which prepare the body to adapt to any situation facing us. The emotion can move in two constructive and destructive directions which this process can act constructively in the shadow of emotion regulation. The manner in which people control their own experience and expression of emotion in the distress situations by employing the strategies such as supervision, repression and cognitive re-evaluation is called emotion regulation (Gross, 2002). Emotion regulation includes all internal and external processes responsible for monitoring, evaluating and modifying emotional reactions, especially its extreme and transient states in order to achieve one's goals and it can be done automatically or controlled, conscious or unconscious. This broad conception consists of numerous processes and regulation strategies including cognitive, physical, social and behavioral aspects (Marles, Wilhelm and Gross, 2006). Accordingly, it can be said that emotion has a powerful effect on people's reasoning and it can help to stabilize through the ways which are yet unknown. In fact, emotion is a complex system developed throughout the history of human evolution and it makes equipped the organism to respond to environmental stimuli and challenges ( Kering \& Moran, 2008). Therefore, people with high emotional regulation can control their emotions in a balanced way and this increases their social adjustment.

4.2 The Second Hypothesis of the Study was that BAS Plays a Role in The Social Adjustment of Adolescents with Conduct Disorder

Pearson correlation coefficient test and regression analysis were used to test this hypothesis and the results showed that there was a significant positive correlation $(\mathrm{p}<0.01)$ between social adjustment and behavioral activation ( $\mathrm{r}=0.31)$. The results obtained from regression analysis and $\beta$ values show that BAS $(\beta=0.33)$ can predict significantly the variations related to the social adjustment of students with conduct disorder. The obtained results are consistent with the results of researches by Hamzlou and Mashhadi (2010), Mashhadi et al. (2009), Favelz (2001), Vitalou \& Rogers (2001), Natan et al. (2010), Adam et al. (2013) and Andrew et al. (2009). Conduct disorder causes many problems in interpersonal relationships of people including the reduction of social adjustment. Adjustment can be said to all strategies applied for handling stressful situations in life by a person, including real or unreal threats (Saduk \& Saduk, 2003). ASlamusky and Don (1996) consider the social adjustment and skill as a process that enables people to understand and predict the behaviors of others, control their own behavior and adjust their social interactions. However, human activities are more influenced by personality factors. Several studies have emphasized the role of behavioral systems in many fields, including early arousal, fear and impulsivity and etc. Behavioral activation system responds to the conditional stimuli of reward and the lack of punishment. Activity and increased sensitivity of this system leads to invoke positive emotions, approach and active avoidance (Gary, 2000). So, when the activity of this system is high in a person with conduct disorder, the conditional stimuli of reward and the positive emotions empowered by other people become active and thus lead to more social adjustment in the person.

\section{Acknowledgements}

The authors acknowledge the adolescents with conduct disorder.

\section{References}

Abolqasemi, A., \& Narimani, M. (2006). Psychological tests. Ardabil: Baghe Rezvan Publications.

Andrew, C., Rapson. G., \& Emily, B. (2009). The relationships between the BIS and BAS, anger and responses to anger. Journal of Personality and Individual Differences, (44) 403-413.

Ashrafi, A. (2006). Evaluation of properties psychometric of Gray-Wilson personality questionnaire. MA. Dissertation. Tehran: Tarbiyat-Modarres University, 67-89. 
Barkley, R. A., \& Fischer, M. (2010). The unique contribution of emotional impulsiveness to impairment in major life activities in hyperactive children as adults. J. Amer Acad Child Adolesc Psychiatry, 49, 503-513.

Biederman, J., Spencer, T., Lomedico, A., Day, H., Petty, C. R., \& Faraone, S. V. (2012). Longitudinal course of deficient emotional self-regulation CBCL profile in youth with ADHD: prospective controlled study. Neuropsy Disease Treat, 8, 267-276.

Carroll, A., Hemingway, F., Bower, J., Ashman, A., Houghton, S., \& Durkin, K. (2006). Impulsivity in Juvenile Delinquency: Differences Among Early-Onset, Late-Onset, and Non- Offenders. Journal of Youth and Adolescence, 35, 519-529.

Corr, P. J. (2004). Reinforcement sensitivity theoryand personality. Neurosci BiobehavRev;28:317-32.

Feldon, J., Gary, J. A., Hamersley, D. R., \& Smith, A. D. (1991). The neuropsychology of schizophrenia. Journal of Behav Brain Sci., 14-9.

Fowles, D. C. (1980). The three arousal model: Implications of gray's two-factor learning theory for heart rate, electro dermal activity and psychopath. Journal of Psychophysiol, 17, 87-104.

Fowles, D. C. (2001). Biological variables in psychopathology: A psychobiological perspective. In H. E. Adams \& P. B. Sutker, Comprehensive Handbook of psychopathology. New York: Kluwer Academic/Plenum, $85-141$.

Garnefski, N., \& Kraaij, V. (2006). Cognitive emotion regulation questionnaire - development of a short 18-item version (CERQ-short). Pers Individ Dif., 41, 1045- 1053.

Garnefski, N., Koopman, H., Kraaij, V., \& Cate, R. T. (2009). Brief report: cognitive emotion regulation strategies and psychological adjustment in adolescents with a chronic disease. J. Adolesc, 32, 449-454.

Gray, J. A. (1995). A model of the limbic system and basal ganglia: Applications to anxiety and schizophrenia. In M. Gazzaniga (Ed.), The cognitive neuroscience. Cambridge: MIT Press, $1165-1176$.

Gray, J. A., \& McNaughton, N. (2000). The neuropsychology of anxiety: An enquiry into the functions of the septohippocampal system. New York: Oxford University, 53-98

Gross, J. (2007). Handbook of emotion regulation. 1st ed. American, New York: The Guilford Press: 42-43.

Gross, J. J. (2002). Emotion regulation: affective, cognitive, and social consequences. Psychophysiology, 39(3), 281.

Ha Adam, K., Robert, J., Coplan, M., Weeks , L., \& Rose, K. (2013). Covering all the BAS's: A closer look at the links between BIS, BAS, and socio-emotional functioning in childhood. Journal of Personality and Individual Differences , (55), 521-526.

Hahn, T. A., Dresler, T. A., Ann-Christine, E. A., Michael, M., Plichta, A., Sebastian, H. A., Polak, T. A., Lesch, F. A., Breuer, F. B., Jakob, B. C., \& Fallgatter, A. J. (2009). Neural response to reward anticipation is modulated by Gray's impulsivity. NeuroImage, 46(3), 1148-1153.

Kheirie, M., Shaeiri, M., Azad, F. P., \& Rasulzade, T. K. (2009). Effect of the triple P-positive parenting program on children with oppositional defiant disorder. J. Bahave Sci., 1(3), 53- 58.

Mashhadi, A., Rasoulzadeh, T. K., Azad, F. P., \& Soltanifar, A. (2009). Comparison of response inhibition and interference control in children with attention deficit / hyperactivity and normal children. Journal of Clinical Psychology, 1(2), 37-50.

Mohammad, E. E. (2005). Textbook of cognitive-behavioral treatment of children with hyperactivity / attention deficit. Tehran: Danzheh Publications.

Mzeh, L. M., \& Mashhadi, A. (2011). Comparison of behavioral inhibition in delinquent adolescents with/without a history of substance abuse and normal adolescents. Journal of Research in Psychological Health, 4, 3\&4, 56-72.

Nathan, A. K., John, T. M., Rosemery, O., \& Nelson, G. (2010). An examination of the relationship between behavioral approach system (BAS) sensitivity and social interaction anxiety. Journal of Anxiety Disorders, (24), 372-378.

Pourfaraj, Omran, M. (2011). Strategies for cognitive regulation of emotions and aggression in students. Contem Psychol, 5(Suppl.), 203-204.

Quay, H. C. (1988). Inhibition and attention deficit hyperactivity disorder. Journal of Abnormal Child 
Psychology, 25, 7-13.

Roisin, M. O. C., Sherry, H. S., \& Margo, C. W. (2009). Distinguishing BAS risk for university students' drinking, smoking, and gambling behaviors. Journal of Personality and Individual Differences, (46), 514 519.

Saduk, B., \& Salak, V. (2003). Summary of Psychiatry, Volume II. Translation: Pour Afkari, N. (1st Ed.). Tehran: Shahrab Publications.

Spencer, T., Faraone, S. V., Surman, C., Petty, C., Clarke, A., Batchelder, H., Wozniak, J., \& Biederman. J. (2011). Towards defining deficient emotional self-regulation in youth with attention deficit hyperactivity disorder using the child behavior check list: A controlled study. Postgrad Med, 123(5), 50-59.

Vitacco, M. J., \& Rogers, R. (2001). Predictors of adolescent psychopathy: The role of impulsivity, hyperactivity, and sensation seeking. Journal of American Academy of Psychiatry and the Law, 29, 374-382.

\section{Copyrights}

Copyright for this article is retained by the author(s), with first publication rights granted to the journal.

This is an open-access article distributed under the terms and conditions of the Creative Commons Attribution license (http://creativecommons.org/licenses/by/3.0/). 